\title{
Age-related macular degeneration: experimental and emerging treatments
}

\author{
Jean Pierre Hubschman \\ Shantan Reddy \\ Steven D Schwartz \\ Jules Stein Eye Institute, \\ Department of Ophthalmology, \\ University of California, \\ David Geffen School of Medicine, \\ Los Angeles, California, USA
}

\begin{abstract}
Purpose: This essay reviews the experimental treatments and new imaging modalities that are currently being explored by investigators to help treat patients with age-related macular degeneration (AMD).

Design: Interpretative essay.

Methods: Literature review and interpretation.

Results: Experimental treatments to preserve vision in patients with exudative AMD include blocking vascular endothelial growth factor (VEGF), binding VEGF, and modulating the VEGF receptors. Investigators are also attempting to block signal transduction with receptor tyrosine kinase inhibitors. Experimental treatments for non-exudative AMD include agents that target inflammation, oxidative stress, and implement immune-modulation. The effectiveness of these newer pharmacologic agents has the potential to grow exponentially when used in combination with new and improved imaging modalities that can help identify disease earlier and follow treatment response more precisely.

Conclusion: With a better understanding, at the genetic and molecular level, of AMD and the development of superior imaging modalities, investigators are able to offer treatment options that may offer unprecedented visual gains while reducing the need for repetitive treatments.

Keywords: age-related macular degeneration, VEGF, SiRNA, PEDF
\end{abstract}

\section{Introduction}

Etiological research suggests that age-related macular degeneration (AMD) is a complex disease caused by the interaction of environmental factors and genetic predisposition. ${ }^{1}$ Though dramatic advances have been made in AMD comprehension and therapeutics, critical issues remain to be addressed. How do we select patients that are most likely to respond to treatment? What will be the local or long-term effect of anti-VEGF therapies regarding side effects and resistance? ${ }^{2,3}$ Is it possible to reduce the frequency of intra-vitreal injections by combining therapies? Is it possible to target other angiogenic molecules?

In this review we will explore the experimental pharmocological agents, new imaging modalities, and genetic advances in AMD that are on the horizon that may help answer some of these questions.

\section{Experimental treatments in exudative AMD}

Angiogenesis is a complex multi-step process regulated by a balance between positive and negative factors. In numerous studies, vascular endothelial growth factor (VEGF) has been implicated as an essential potent positive regulatory factor in angiogenesis. ${ }^{2}$ There are, however, many other positive factors in angiogenesis including fibroblast growth factors, angiopoietins, TGF-a and -b, hepatocyte growth factors, connective tissue growth factors, and IL-8. Endogenous negative regulatory factors also exist, which include thrombospondin, angiostatin, endostatin, and pigment epithelium
Correspondence: Jean-Pierre Hubschman Jules Stein Eye Institute - UCLA, 200 Stein Plaza, 90095 Los Angeles, California, USA

Tel +l 310 2065004

$\mathrm{Fax}+\mathrm{I} 3107947905$

Email hubschman@jsei.ucla.edu 
derived factor (PEDF). ${ }^{4}$ Moreover, recent information supports that the decline of the ocular down-regulatory immune environment plays an important role in AMD, and it is suggested that immunotherapy could positively alter the course of the disease. ${ }^{5}$

\section{VEGF pathway Blocking VEGF expression}

RNA interference (RNAi) is a new method to inhibit the production of VEGF by the post-transcriptional silencing of gene expression. ${ }^{6-8}$ Small interference RNA (si-RNA) is a double stranded RNA (ds-RNA) consisting of 21 to 22 nucleotides which is incorporated into the cell. Small interference RNA silences the expression of a protein in a specific and potent fashion by utilizing ds-RNA molecules that target a particular messenger RNA (mRNA). The advantage of RNAi over anti-sense and ribozyme is the ability of RNAi to amplify the destruction of mRNA by activating a protein complex called RNA-induced silencing complex (RISC). Unlike single stranded anti-sense RNA, RISC uses the ds-RNA sequence to seek and destroy homologous mRNA in a multiple turnover kinetic fashion. ${ }^{9,10}$ One ds-RNA can destroy hundreds of targeted mRNA (cleaved and then digested), which will result in the silencing of thousands of molecules. ${ }^{11}$ It has been shown that si-RNA against VEGF is a potent strategy for inhibiting growth and leakage of CNV in neovascular AMD. ${ }^{12-14}$ Small interference RNA down regulates the VEGF production (by post-transcriptional gene silencing) but has no effect on the VEGF already produced and may explain why its effectiveness is often delayed. Nevertheless, siRNA is a promising treatment for consequent and long-acting blockage of the VEGF. A phase II study (C.A.R.E), a randomized, doublemasked, controlled, dose comparison of bevasiranib (formerly Cand5) for the treatment of neovascular CNV, in which 3 doses ( $0.2 \mathrm{mg}, 1.5 \mathrm{mg}, 3 \mathrm{mg}$ ) were administered by 2 injections, 6 weeks apart, to 127 subjects has been conducted. Approximately $78 \%$ of subjects lost $<15$ letters at the 12-week endpoint. An initial worsening of visual acuity and increase in CNV size followed by a reversal of both parameters in the second month suggest that bevasiranib is able to turn off VEGF production for prolonged periods but that the clinical effect is not seen until after all the VEGF already present in the eye has been cleared. No adverse effects, local or general, were described except one case of transient vitritis (within the $3 \mathrm{mg}$ group). Future studies incorporating initial neutralization of VEGF with anti-VEGF agents are planned. ${ }^{15}$

\section{Binding VEGF}

The successful application of anti-VEGF approaches in the clinic is obviously a turning point in AMD. Three different molecules described previously (pegaptanib, ranibizumab, and bevacizumab) bind VEGF and induce inhibition of CNV.

Another option is to bind and inhibit VEGF by using VEGF Trap. It is a recombinant soluble VEGF receptor protein in which the binding domains of VEGF receptors one and two are combined with the Fc portion of immunoglobulin G. The receptor portion of the molecule has a very high affinity for all types of VEGF (VEGF-A, -B, -C, -D, and PGF). VEGF Trap presents a high potency for neutralizing all forms of VEGF. The VEGF Trap continues to have a persistent effect even at low concentration since its bulky Fc portion allows it to clear from the body slowly. It offers a longer interim between injections without losing its efficacy. ${ }^{16}$ The efficacy of VEGF Trap in the suppression of CNV has been shown in multiple studies. ${ }^{17} \mathrm{~A}$ phase I trial assessing the safety, pharmacokinetics, and biological activity of intravenous administration of VEGF Trap in neovascular AMD subjects has been conducted. ${ }^{18}$ It showed that the VEGF Trap inhibited the growth of new blood vessels when given intravenously, as well as when administered directly into the eye. The maximum tolerated dose of iv VEGF Trap in the study was $1 \mathrm{mg} / \mathrm{kg}$. This dose resulted in elimination of approximately $60 \%$ of the excess retinal thickness after either single or multiple administrations. The side effects described were moderate in severity and included hypertension and proteinuria but no thrombo-embolic events.

\section{Modulating VEGF receptors}

Vascular endothelial growth factor receptor 1 and mainly VEGF-R2 are considered to be important in the VEGF angiogenic cascade in neovascular AMD. ${ }^{19}$ Vascular endothelial growth factor receptors can be inhibited in two ways. One can use siRNA (described previously) directed against VEGF receptor mRNA or a chimeric protein of VEGF coupled to a toxin.

A siRNA technique, called Sirna-027, targeted to VEGF-R1 mRNA, was found to be effective in different animal models in reducing choroidal and retinal neovascularization. A phase I clinical trial including 14 subjects with neovascular AMD showed that the drug was well tolerated and induced a reduction in retinal thickness in 6 of the 7 subjects studied. ${ }^{20}$ These data suggest that VEGF-R1 plays an important role in the development $\mathrm{CNV}$ and that targeting VEGF-R1 mRNA with si-RNA has therapeutic potential. ${ }^{21}$ 
The administration of a chimeric protein consisting of VEGF 121 coupled to the toxin gelonin (VEGF/rGel) has been tested in mice. After intravenous injection of $45 \mathrm{mg} / \mathrm{kg} \mathrm{VEGF} / \mathrm{rGel}$, there was immuno-fluorescent staining for rGel within choroidal neovascularization and regression of the neovascularization occurred in the mice, demonstrating successful vascular targeting via the systemic circulation. The strategy of vascular targeting can be applied to non-malignant neovascular diseases and could serve as the basis for new treatments to reduce established ocular neovascularization. ${ }^{22}$

\section{Blocking VEGF signal transduction}

Vascular endothelial growth factor signals through two tyrosine kinase receptors, Flt 1 (VEGFR1) and KDR (VEGFR2, Flk-1). New classes of drugs called receptor tyrosine kinase inhibitors are ATP-competitive inhibitors, and they can block the receptor for tyrosine kinases, including all VEGF receptors as well as the PDGF receptors. ${ }^{23-25}$ The assessment of a KDR (VEGFR2) kinase inhibitor in two well-established models of ocular neovascularization following oral administration has been described. ${ }^{26}$ At doses of $100 \mathrm{mg} / \mathrm{kg}$, the KDR kinase inhibitor resulted in a $98 \%$ reduction in lesion size in the rat CNV model. Doses of $30 \mathrm{mg} / \mathrm{kg}$ of the inhibitor showed a $70 \%$ reduction in lesion size in the laser-induced CNV model. The researchers concluded that the oral dosing of the described KDR kinase inhibitor effectively inhibits ocular neovascularization in animal models. Another study evaluated the SU11248 (multi-targeted receptor tyrosine kinase inhibitor) on murine CNV models, which showed that oral administration of this compound is potentially beneficial in treating $\mathrm{CNV}$ caused by AMD. ${ }^{27}$ A phase III study evaluating the same product in oncology showed that it was well tolerated in humans. A randomized, masked, single and multiple-dose, sequential dose-escalation phase I-II study of AG-013958 (another receptor tyrosine kinase inhibitor) in neovascular AMD was halted in July 2006, as the drug was not providing the anticipated results. A phase II study evaluating another VEGFR tyrosine kinase inhibitor (vatalanib) started in July 2007.

\section{Inhibition of intracellular effects of VEGF}

Steroids have angiostatic effects in animal models of CNV but present side effects because of their mineral and glucocorticoid activities (high intraocular pressure and cataract formation). A new class of angiostatic agents, derived from a steroid called cortisene, has been developed. Anecortave acetate $\left(\right.$ Retaane $\left.^{\circledR}\right)$ can inhibit angiogenesis in animal models.
Anecortave acetate affects the angiogenic proteolytic cascade at multiple levels. It can partially suppress the urokinase activator and pro-matrix metalloproteinase expression and inhibit VEGF expression and insulin-like growth factor-1. It has been evaluated in many studies alone and in combination with other therapies. ${ }^{28-30}$ In the monotherapy trial, the administration of $15 \mathrm{mg}$ by a posterior juxta-scleral depot at 6-month intervals resulted in significant benefits (visual acuity stabilization and prevention of severe vision loss) in comparison with placebo. ${ }^{31}$ A phase III study comparing anecortave acetate $15 \mathrm{mg}$ to vPDT for maintaining vision in subjects with predominantly classic choroidal neovascularization failed to demonstrate non-inferiority of anecortave acetate to vPDT. ${ }^{32}$ The study did show that anecortave acetate at $15 \mathrm{mg}$ was safe and well tolerated in the overall subject population. Anecortave acetate is currently being tested (AART study) as a preventive agent in intermediate AMD subjects who are at risk of progressing to exudative AMD.

\section{Counteracting VEGF}

Several endogenous physiological inhibitors of angiogenesis have been identified and include fragments of matrix components, endostatins, angiostatins, and pigment epitheliumderived factor (PEDF). ${ }^{33-35}$ Pigment epithelium-derived factor is normally produced in the eye and serves two important functions: to regulate normal blood vessel growth and to protect the photoreceptors. Pigment epithelium-derived factor also inhibits endothelial cell migration in vitro and is significantly decreased in eyes that harbor AMD. It has been shown that adenoviral-mediated intraocular delivery of PEDF reduces CNV formation. ${ }^{36,37}$ Ad-PEDF is an intravitreal or peri-ocular injected transgene which uses a DNA carrier (virus vector) to deliver the PEDF gene, resulting in the local production of PEDF in the treated eye. A dose escalation phase I, multi-center clinical trial including 28 subjects with neovascular AMD showed no dose-limiting toxicity or adverse effects. Other gene therapies evaluated in animal studies demonstrated their potential in the treatment of CNV. Short hairpin (sh) RNA, which targets VEGF from adenovirus vectors, allows potent attenuation of VEGF and prevents $\mathrm{CNV} .{ }^{38}$ Another gene delivery angiogenesis inhibitor, vasostatin, has been tested and shown to reduce the size of the CNV lesion. ${ }^{39}$

\section{Other anti-angiogenic strategies (non-VEGF related)}

The turnover of the new drugs assessed in exudative AMD is fast. Studies of drugs such as combretastatin A-4 phosphate 
(a structural analog to colchicines) and squalamine lactate (broad spectrum aminosterol antibiotic isolated from the cartilage of the dogfish shark), which were considered very promising a few months ago were recently stopped. ${ }^{40-42}$

Given the role of the immune system in AMD, new strategies addressing these mechanisms, both systemic and local, alone or in combination with anti-VEGF drugs, seem to be appropriate. ${ }^{5}$ In that way, new drugs such as infliximab (Remicade $^{\circledR}$ ) (directed against TNF axis), rapamycin (anti-angiogenic and anti-immune properties), and daclizumab (antibody directed against IL-2 receptor) are being tested. Other areas of research are at the preliminary stages of human development. ${ }^{43}$ New blood vessels in postnatal events are related to angiogenesis but also to vasculogenesis, which corresponds to the recruitment and differentiation of bone marrow derived angioblasts (endothelial progenitor cells or EPC into mature endothelial cells). ${ }^{44}$ Inflammation, through macrophages, also appears to play an important role in the angiogenic cascade. ${ }^{45}$ Proteases (plasmin and MMPs) play an important role in tissue remodeling and cell recruitment associated with pathological angiogenesis and should also be carefully explored. ${ }^{46}$

\section{Experimental treatments in atrophic AMD}

Even though the atrophic form of AMD represents $90 \%$ of all cases of AMD, there is no effective treatment available. New approaches are now being considered to prevent atrophic AMD, since we now have a better understanding of the pathological processes involved. Atrophic AMD is a neurodegenerative disease of the retina. The retinal pigment epithelium (RPE) seems to be the target of inflammation, oxidative stress, and possibly accumulation of lipofuscin and prevention of these factors may delay the progression of AMD. ${ }^{47}$

\section{Targeting oxidative stress}

Oxidative stress of the RPE and photoreceptors play a major role in the development of AMD. The AREDS study data have shown a preventive effect of antioxidant therapy in delaying the progression of atrophic AMD. It is thought that a more powerful antioxidant cocktail including free radical scavengers, catalytic mimetics, and inhibitors of ROS-generating enzymes as well as metal chelators may have better efficacy in preventing the progression of AMD.

\section{Targeting inflammation}

The critical role of inflammation in the pathophysiology of atrophic AMD has been established by the recent discovery regarding the association of complement factor $\mathrm{H}$ mutations with AMD. The factor $\mathrm{H}$ mutation is responsible of the increased activation of the alternative complement pathway. A potent inhibitor of the alternative pathway may have an effective role as an anti-AMD treatment. A new potent inhibitor of complement factor C3, POT-4, was assessed in a preclinical safety study of intra-vitreal and systemic administration in cynomologus monkeys. No local or systemic toxicity of POT-4 was described. A phase II evaluation was to start in $2008 .^{32}$

\section{Immune-modulation}

The reactive gliosis via the Muller cells is involved in impairing vision in the atrophic forms of AMD. A down-regulation of reactive gliosis may represent a new therapeutic area. Copaxone $^{\circledR}$ is a new immuno-modulatory therapy currently tested in a prospective, randomized, double-masked, shamcontrolled pilot study. At 12 weeks, the eyes treated with Copaxone showed a reduction of $66 \%$ of the drusen versus $0.6 \%$ in the sham group. These preliminary results showed that Copaxone might have the potential to reduce drusen and prevent the evolution toward atrophic AMD. ${ }^{48}$

Cell replacement strategy is a treatment venue currently being explored. The autologous transplantation of retinal stem cells may allow photoreceptor regeneration, if the synaptic connections between the RPE cells are established.

\section{Experimental treatment in end stage AMD}

A visual prosthetic implant including a fixed-focus telescopic system works as a wide-angle and produces a telephoto effect that enlarges the objects in a patient's central visual field. A phase II/III trial including 217 subjects with bilateral end stage AMD is ongoing. The results at 1 year show 3 lines improvement regarding distance visual acuity in $67 \%$ of the implanted eyes versus $13 \%$ in control eyes. Near vision improved in $53 \%$ of implanted eyes versus $10 \%$ in the control eyes. The results were similar at 2 years with a mean improvement of 3.2 lines in distance visual acuity and 2.9 lines in near visual acuity. The main limitation and FDA concern regarding this interesting intraocular device is the endothelial cell loss due to trauma from the implantation procedure (20\% at 3 months, $25.3 \%$ at 12 months and $27.8 \%$ at 2 years). ${ }^{49,50}$

\section{New imaging modalities}

Over the past few years imaging modalities have evolved significantly growing from the body of research that suggests 
current methods of neovascular detection identify pathology too late in the course of the disease. Previous studies such as TAP, VIP, and others used fluorescein angiography (FA) to determine the need for treatment, while other studies implemented indocyanine green angiography (ICG). More recent pharmaceutical trials are implementing optical coherence tomography (OCT), scanning laser ophthalmoscopy (SLO), fundus auto-fluorescence, and functional imaging such as fundus-related micro-perimetry. The use of these newer imaging modalities allows for early detecting, identifying prognostic predictors, and monitoring treatment response in a less invasive way as compared to FA alone.

\section{OCT}

Optical coherence tomography (OCT) is a non-contact, non-invasive low coherence imaging device that produces a high resolution, cross-sectional image of the retina. This device has improved the visualization of the vitreo-retinal, intra-retinal, and sub-retinal structures and has added to our understanding of pathologic processes. The commercially available instrument, stratus OCT-3 (Carl Zeiss Meditec, Dublin, Cal.), employs a time-domain OCT technique that requires long acquisition times and provides axial and lateral resolutions on the order of $15 \mu \mathrm{m}$. The slow speed and relatively low resolution of this system may not allow adequate information on some types of neovascular complexes. On the other hand, Fourier-domain (also known as spectral domain) optical coherence tomography (Fd-OCT or SD-OCT) is a new imaging technique that utilizes the Fourier transformation to gather depth data from the spectra of the OCT signal. The Fd-OCT does not require the time for mechanical movement of the scanning mirror to obtain depth information, as is required for conventional time-domain systems used in clinics today. Fd-OCT has increased speed of data collection by a factor 50 ( time domain OCT functions at $400 \mathrm{~A}$-scans/sec, while Fd-OCT systems scans at 20,000 A-scans/sec). The benefits of the Fd-OCT imaging are numerous: greater density of sampling and better image quality ( $3 \mu \mathrm{m}$ axial, $10 \mu \mathrm{m}$ transverse), covers more areas of the retina, decreased patient movement artifact.

Thanks to the new Fd-OCT systems available, high resolution B-scan images of the macula can then be obtained from the faster acquisition time allowing for three-dimensional reconstructions of neovascular complexes. It can provide details of the macula that may be missed by time-domain OCT-3.

The Spectralis HRA + OCT (Heildelberg, Germany) combines spectral domain OCT with laser angiography can scan the retina at 40000 scans per second creating highly detailed images of retinal structures. Because the OCT and FA images are captured simultaneously, physicians can be assured of the exact location of the area of interest and can correlate the outer visible retina with the internal structure. Its advantage comes from the fact that a clinician can look at the exact same position in the retina on repeated studies over repeated visits. It is also useful to identify small abnormalities and be confident that you are actually imaging that particular abnormality. The Spectralis can register its cross-sectional images to either, FA, ICG, or AF to create an accurate and reliable reference point.

Though OCT was initially used for diabetic edema, studies have shown that it can help both in the detection and classification of choroidal neovascularization as well as determining the need for further follow-up and re-treatment in patients with AMD. ${ }^{51-53}$ It is useful in the initial detection of AMD through follow-up and proved effective in detecting the presence of sub-retinal and intra-retinal fluid, thereby identifying potentially treatable lesions. However, OCT should not take the place of FA, but used in conjunction since it could not identify the exact components of the lesion. ${ }^{54}$

OCT can also screen which patients require FA on follow-up and help determine the need for re-treatment. Fluorescein angiography alone is subject to variability among observers and difficulties in quantifying true leakage, whereas OCT combined with FA will increase both the sensitivity and specificity in determining activity. ${ }^{55}$ Furthermore, in the era of monthly treatments with pharmaco-therapeutic agents, using a less invasive imaging modality, such as OCT, is safer, less expensive, and more practical for monitoring monthly treatment response. Therefore, use of FA in conjunction with OCT will likely be the standard of care in the near future.

\section{Fundus auto-fluorescence}

Fundus auto-fluorescence is an imaging modality that has the ability to determine the health of the RPE prior to overt atrophy. By identifying the build up of lipofuscin accumulating within the RPE, it can identify disturbances within the RPE. Studies have shown that lipofuscin accumulation may be a prognosticating predictor for AMD. ${ }^{56}$ Other advantages of AF imaging, other than being another non-invasive imaging system, include its ability the qualitatively evaluate the risk of AMD progression by mapping retinal auto-fluorescence patterns over time. ${ }^{57}$ However, the reports are limited and somewhat conflicting and further study is warranted. Autofluorescence is also useful for mapping GA and has shown to be superior to fundus photography or FA in this regard. ${ }^{58}$ 
Therefore, this imaging modality may be useful for monitoring experimental treatments intended to slow down or halt atrophic AMD. The current literature, however, consists only of nonrandomized cases series. This was the impetus of The Fundus Auto-fluorescence in Age-related Macular Degeneration Study Group (FAM study group), a multi-center study. The goal of the study is to investigate the correlation between fundus auto-fluorescence and the natural history of AMD and identify high-risk auto-fluorescence characteristics that can predict patients who will progress to late AMD. ${ }^{59}$

\section{SLO/OCT}

Image acquisition in SLO occurs by the use of a narrow infrared light directed towards the retina surface. It was developed as an alternative to traditional photography with FA and offers advantages over traditional FA. Pupillary dilation is not mandatory and it can penetrate media. ${ }^{60}$ With the recent addition of the OCT to the confocal SLO, cross-sectional images can be obtained giving information on deep retinal structures. Its applications include the ability to image early transit phases to identify feeder vessel when used with FA and allows AF imaging to be unaffected by anterior segment pathology. In addition, it can allow for more precise quantification of GA to enable us to follow treatment response in cases of atrophic AMD. When time domain OCT is combined with SLO (SLO/OCT), scans can be generated that corresponds pixel-to-pixel to the confocal image, allowing for improved registration. This allows the treating ophthalmologist to detect small lesions with sub-retinal fluid that may have been missed with either imaging modality alone.

\section{Fundus-related microperimetry}

Fundus-related microperimetry is a functional imaging system that uses test stimuli that are projected onto the retina while the fundus is viewed with an infrared camera. A predefined automatic macula test pattern is used centered onto the fovea. The light stimuli are presented randomly during the examination as in standard static perimetry. High-speed image-tracking software of the system compensates for eye movements and ensures spatial correlation. Functional, micro-perimetric assessment may be more important in the follow-up than visual acuity testing since it can identify para-foveal scotomas even in eyes with preserved visual acuity or areas of visual preservation near a complete scotoma. This imaging modality may then be able to better quantify subtle change in vision after treatment and help guide in patient visual rehabilitation.

\section{Genetics}

AMD is a complex disease caused by a combination of genetic predisposition and environmental factors. Some of the important genes implicated in AMD are as follows. The complement factor $\mathrm{H}(\mathrm{CFH})$ gene produces a protein that inhibits the complement cascade and it is located on chromosome 1, the region 1q25-3, and it is associated with 7.4-fold increase for AMD in individuals homozygous for the risk allele. Seddon showed that $\mathrm{CFH}$ is related to both geographic atrophy and CNV after controlling for other environmental risk factors. ${ }^{61}$ Three loci on chromosome 10q26, PLEKHA1, LOC387715, and HTRA1 have been linked to AMD. ${ }^{62}$ Jakobsdottir found that SNPrs10490924 within the 10q26 chromosome, the LOC387715/HTRA1 confers a population attributable risk of $57 \% .{ }^{63}$ Other genes identified were the adenosine triphosphate binding cassette rim protein (ABCR), which has been implicated previously in Stargardt's disease, may account for 3\% of AMD cases. ${ }^{64,65}$ The CX3CR1 gene located on chromosome 3 is a chemokine receptor expressed in retinal cells and has also been implicated in AMD along with mutations in chromosome 6q, which is involved in the elongation of very long chain fatty acids (EVOVL4). ${ }^{66}$ Furthermore, mutations in chromosome 14q, which codes for fibulin-5, a protein localized to Bruch's membrane and mutations in chromosome 19q, which codes for ApoE, a major transporter of lipids and cholesterol in the nervous system have also been implicated in AMD. ${ }^{67}$ A number of various factors have already been identified which are involved in the pathogenesis of AMD, and this may eventually lead to screening of high risk individuals to facilitate and earlier diagnosis and help prevent end stage pathology. Though major advances have been made, the identification of genetic factors has not resulted in strategies to modify, halt, or treat the disease thus far. Additional studies and trials are warranted.

\section{Conclusion}

The complexity of AMD and our limited understanding of it, at the molecular level, makes finding effective longterm treatment options difficult. However, over the last few years, new research has led to the discovery of various genes implicated in its pathogenesis and has allowed investigators to explore new treatments options that can target the disease at various molecular levels. We have reviewed these experimental treatments in detail, but only over time and after future prospective studies will we be able to evaluate their efficacy utility. The new and superior imaging modalities that are emerging may offer further benefits when combined 
with these experimental treatments by allowing us to follow patients more precisely and intervene earlier. The future of AMD looks promising, though, as we gain insights into the genetic makeup of this intricate disease and begin using new treat options in combination with more sophisticated imaging devices.

\section{Disclosures}

No financial support or grants were utilized for this study. The authors do not have financial disclosures or competing interests in the presented topic.

\section{References}

1. Rattner A, Nathans J. Macular degeneration: recent advances and therapeutic opportunities. Nat Rev Neurosci. 2006;7(11):860-72.

2. Ferrara N, Kerbel RS. Angiogenesis as a therapeutic target. Nature. 2005;438(7070):967-74.

3. Verheul HM, Pinedo HM. Possible molecular mechanisms involved in the toxicity of angiogenesis inhibition. Nat Rev Cancer. 2007;7(6):475-85.

4. Folkman J. Role of angiogenesis in tumor growth and metastasis. Semin Oncol. 2002;29(6 Suppl 16):15-8.

5. Nussenblatt RB, Ferris F. Age-related macular degeneration and the immune response: implications for therapy. Am J Ophthalmol. 2007; 144(4):618-26.

6. Elbashir SM, Harborth J, Lendeckel W, Yalcin A, Weber K, Tuschl T. Duplexes of 21-nucleotide RNAs mediate RNA interference in cultured mammalian cells. Nature. 2001;411(6836):494-8.

7. Fire A, Xu S, Montgomery MK, Kostas SA, Driver SE, Mello CC. Potent and specific genetic interference by double-stranded RNA in Caenorhabditis elegans. Nature. 1998;391(6669):806-11.

8. Whelan J. First clinical data on RNAi. Drug Discov Today. 2005;10(15):1014-5.

9. Hadj-Slimane R, Lepelletier Y, Lopez N, Garbay C, Raynaud F. Short interfering RNA (siRNA), a novel therapeutic tool acting on angiogenesis. Biochimie. 2007;89(10):1234-44.

10. Tolentino M. Interference RNA technology in the treatment of CNV. Ophthalmol Clin North Am. 2006;19(3):393-9.

11. Hannon GJ. RNA interference. Nature. 2002;418(6894):244-51.

12. Kim DH, Rossi JJ, Strategies for silencing human disease using RNA interference, Nat Rev Genet. 2007;8(3):173-84.

13. Reich SJ, Fosnot J, Kuroki A, et al. Small interfering RNA (siRNA) targeting VEGF effectively inhibits ocular neovascularization in a mouse model. Mol Vis. 2003;9:210-6.

14. Tolentino MJ, Brucker AJ, Fosnot J, Ying GS, Wu IH, Malik G, Wan S, Reich SJ. Intravitreal injection of vascular endothelial growth factor small interfering RNA inhibits growth and leakage in a nonhuman primate, laser-induced model of choroidal neovascularization. Retina. 2004;24(4):660.

15. Singerman LJ. Bevasiranib for treatment of AMD and DME. Oral presentation at The Retina Society, Boston Sept 28, 2007.

16. Holash J, Davis S, Papadopoulos N and al. VEGF-Trap: a VEGF blocker with potent antitumor effects. Proc Natl Acad Sci US A. 2002;99(17):11393-8.

17. Saishin Y, Takahashi K, Lima E, et al. RVEGF-TRAP(R1R2) suppresses choroidal neovascularization and VEGF-induced breakdown of the blood-retinal barrier. J Cell Physiol. 2003;195(2):241-8.

18. Nguyen QD, Shah SM, Hafiz G, et al. CLEAR-AMD 1 Study Group. A phase I trial of an IV-administered vascular endothelial growth factor trap for treatment in patients with choroidal neovascularization due to age-related macular degeneration. Ophthalmology. 2006;113(9):1522. e1-1522.e14.
19. Campochiaro PA. Potential applications for RNAi to probe pathogenesis and develop new treatments for ocular disorders. Gene Ther. 2006; 13(6):559-62.

20. Whelan J. First clinical data on RNAi. Drug Discov Today. 2005; 10(15):1014-5.

21. Shen J, Samul R, Silva RL, et al. Suppression of ocular neovascularization with siRNA targeting VEGF receptor 1. Gene Ther. 2006;13(3):225-34.

22. Akiyama H, Mohamedali KA, E Silva RL, et al. Vascular targeting of ocular neovascularization with a vascular endothelial growth factor121. gelonin chimeric protein. Mol Pharmacol. 2005;68(6):1543-50.

23. Saishin Y, Silva RL, Saishin Y, et al. Periocular injection of microspheres containing PKC412 inhibits choroidal neovascularization in a porcine model. Invest Ophthalmol Vis Sci. 2003;44(11):4989-93.

24. Takeda A, Hata Y, Shiose S, et al. Suppression of experimental choroidal neovascularization utilizing KDR selective receptor tyrosine kinase inhibitor. Graefes Arch Clin Exp Ophthalmol. 2003;241(9):765-72.

25. Wang FE, Shi G, Niesman MR, Rewolinski DA, Miller SS. Receptor tyrosine kinase inhibitors AG013764 and AG013711 reduce choroidal neovascularization in rat eye. Exp Eye Res. 2007;84(5):922-33.

26. Kinose F, Roscilli G, Lamartina S, et al. Inhibition of retinal and choroidal neovascularization by a novel KDR kinase inhibitor. Mol Vis. 2005;11:366-73.

27. Takahashi H, Obata R, Tamaki Y. A novel vascular endothelial growth factor receptor 2 inhibitor, SU11248, suppresses choroidal neovascularization in vivo. $J$ Ocul Pharmacol Ther. 2006;22(4):213-8.

28. Regillo CD, D’Amico DJ, Mieler WF, Schneebaum C, Beasley CH, Sullins GT. Clinical safety profile of posterior juxtascleral depot administration of anecortave acetate $15 \mathrm{mg}$ suspension as primary therapy or adjunctive therapy with photodynamic therapy for treatment of wet age-related macular degeneration. Surv Ophthalmol. 2007;52 (Suppl 1):S70-8.

29. Russell SR, Hudson HL, Jerdan JA; Anecortave Acetate Clinical Study Group. Anecortave acetate for the treatment of exudative age-related macular degeneration - a review of clinical outcomes. Surv Ophthalmol. 2007;52 (Suppl 1):S79-90.

30. Schmidt-Erfurth U, Michels S, Michels R, Aue A. Anecortave acetate for the treatment of subfoveal choroidal neovascularization secondary to age-related macular degeneration. Eur J Ophthalmol. 2005;15(4):482-5

31. D'Amico DJ, Goldberg MF, Hudson H, et al. Anecortave Acetate Clinical Study Group. Anecortave acetate as monotherapy for treatment of subfoveal neovascularization in age-related macular degeneration: twelve-month clinical outcomes. Ophthalmology. 2003; 110(12):2372-83; discussion 2384-5.

32. Slakter JS. Complement C3 inhibitor POT-4: Pre-clinical safety of intra-vitreal and systemic administration. Oral presentation, The Retina Society, Boston. September 2007.

33. Eichler W, Yafai Y, Wiedemann P, Fengler D. Antineovascular agents in the treatment of eye diseases. Curr Pharm Des. 2006;12(21):2645-60.

34. Saishin Y, Silva RL, Saishin Y, et al. Periocular gene transfer of pigment epithelium-derived factor inhibits choroidal neovascularization in a human-sized eye. Hum Gene Ther. 2005;16(4):473-8.

35. Tong JP, Yao YF. Contribution of VEGF and PEDF to choroidal angiogenesis: a need for balanced expressions. Clin Biochem. 2006;39(3):267-76.

36. Duh EJ, Yang HS, Suzuma I, et al. Pigment epithelium-derived factor suppresses ischemia-induced retinal neovascularization and VEGF-induced migration and growth. Invest Ophthalmol Vis Sci. 2002;43(3):821-9.

37. Mori K, Gehlbach P, Ando A, McVey D, Wei L, Campochiaro PA. Regression of ocular neovascularization in response to increased expression of pigment epithelium-derived factor. Invest Ophthalmol Vis Sci. 2002;43(7):2428-34. 
38. Cashman SM, Bowman L, Christofferson J, Kumar-Singh R. Inhibition of choroidal neovascularization by adenovirus-mediated delivery of short hairpin RNAs targeting VEGF as a potential therapy for AMD. Invest Ophthalmol Vis Sci. 2006;47(8):3496-504.

39. Sheu SJ, Chou LC, Bee YS, et al. Suppression of choroidal neovascularization by intramuscular polymer-based gene delivery of vasostatin. Exp Eye Res. 2005 Dec;81(6):673-9. Epub 2005 Jun 20.

40. Higgins RD, Yan Y, Geng Y, Zasloff M, Williams JI. Regression of retinopathy by squalamine in a mouse model. Pediatr Res. 2004;56(1):144-9.

41. Higgins RD, Sanders RJ, Yan Y, Zasloff M, Williams JI. Squalamine improves retinal neovascularization. Invest Ophthalmol Vis Sci. 2000;41(6):1507-12.

42. Nambu H, Nambu R, Melia M, Campochiaro PA. Combretastatin A-4 phosphate suppresses development and induces regression of choroidal neovascularization. Invest Ophthalmol Vis Sci. 2003;44(8):3650-5.

43. Emerson MV, Lauer AK. Emerging therapies for the treatment of neovascular age-related macular degeneration and diabetic macular edema. BioDrugs. 2007;21(4):245-57.

44. Sengupta N, Caballero S, Mames RN, Butler JM, Scott EW, Grant MB. The role of adult bone marrow-derived stem cells in choroidal neovascularization. Invest Ophthalmol Vis Sci. 2003;44(11):4908-13.

45. Espinosa-Heidmann DG, Suner IJ, Hernandez EP, Monroy D, Csaky KG, Cousins SW. Macrophage depletion diminishes lesion size and severity in experimental choroidal neovascularization. Invest Ophthalmol Vis Sci. 2003;44(8):3586-92.

46. Noel A, Jost M, Lambert V, Lecomte J, Rakic JM. Anti-angiogenic therapy of exudative age-related macular degeneration: current progress and emerging concepts.Trends Mol Med. 2007;13(8):345-52.

47. Petrukhin K. New therapeutic targets in atrophic age-related macular degeneration. Expert Opin Ther Targets. 2007;11(5):625-39.

48. Landa G. Immune-based systemic therapy with copaxone for dry AMD. The Retina society, Boston, Sept 29, 2007.

49. Hudson HL, Lane SS, Heier JS, et al. IMT-002 Study Group. Implantable miniature telescope for the treatment of visual acuity loss resulting from end-stage age-related macular degeneration: 1-year results. Ophthalmology. 2006;113(11):1987-2001.

50. Lane SS, Kuppermann BD. The Implantable Miniature Telescope for macular degeneration. Curr Opin Ophthalmol. 2006; 17(1):94-8.

51. Hee MR, Baumal CR, Puliafito CA, et al. Optical coherence tomography of age-related macular degeneration and choroidal neovascularization. Ophthalmology. 1996;103:1260-70.

52. Rogers AH, Martidis A, Greenberg PB, et al. Optical coherence tomography findings following photodynamic therapy of choroidal neovascularization. Am J Ophthalmol. 2002;134:566-76.
53. Rosenfeld PJ, Moshfeghi AA, Puliafito CA. Optical coherence tomography findings after an intravitreal injection of bevacizumab (avastin) for neovascular. Ophthalmic Surg Lasers Imaging. 2005;36(4):331-5.

54. Sandhu SS, Talks SJ. Correlation of optical coherence tomography, with or without additional colour fundus photography, with stereo fundus fluorescein angiography in diagnosing choroidal neovascular membranes. Br J Ophthalmol. 2005;89:967-70.

55. Salinas-Alaman A, Garcia-Layana A, Maldonado MJ, et al. Using optical coherence tomography to monitor photodynamic therapy in age related macular degeneration. Am J Ophthalmol. 2005;140:23-8.

56. Dorey $\mathrm{CK}, \mathrm{Wu} \mathrm{G}$, Ebenstein D, et al. Cell loss in the aging retina. Relationship to lipofuscin accumulation and macular degeneration. Invest Ophthalmol Vis Sci. 1989;30:1691-9.

57. Spaide RF. Fundus autofluorescence and age-related macular degeneration. Ophthalmology. 2003;110:392-9.

58. Holz FG, Bellmann C, Margaritidis M, et al. Patterns of increased in vivo fundus autofluorescence in the junctional zone of geographic atrophy of the retinal pigment epithelium associated with age-related macular degeneration. Graefes Arch Clin Exp Ophthalmol. 1999;237:145-52.

59. Einbock W, Moessner A, Schnurrbusch UE, et al. FAM Study Group. Changes in fundus autofluorescence in patients with age-related maculopathy. Correlation to visual function: a prospective study. Graefes Arch Clin Exp Ophthalmol. 2005;243:300-5.

60. Kirkpatrick JN, Manivannan A, Gupta AK, et al. Fundus imaging in patients with cataract: role for a variable wavelength scanning laser ophthalmoscope. Br J Ophthalmol. 1995;79:892-9.

61. Seddon JM, Cote J, Page WF, et al. The US twin study of age-related macular degeneration: relative roles of genetic and environmental influences. Arch Ophthalmol. 2005;123:321-7.

62. Despriet DD, Klaver CC, Witteman JC, et al. Complement factor H polymorphism, complement activators, and risk of age-related macular degeneration. JAMA. 2006;296:301-9.

63. Jakobsdottir J, Conley YP, Weeks DE, Mah TS, Ferrell RE, Gorin MB. Susceptibility genes for age-related maculopathy on chromosome 10q26. Am J Hum Genet. 2005;77(3):389-407.

64. Allikmets R, Wasserman WW, Hutchinson A, et al. Organization of the ABCR gene: analysis of promoter and splice junction sequences. Gene. 1998;215(1):111-22.

65. Allikmets R, Shroyer NF, Singh N, et al. Mutation of the Stargardt disease gene (ABCR) in age-related macular degeneration. Science. 1997;277(5333):1805-7.

66. Tuo J, Smith BC, Bojanowski CM, et al. The involvement of sequence variation and expression of CX3CR1 in the pathogenesis of age-related macular degeneration. FASEB J. 2004;18(11):1297-9.

67. Stone EM, Braun TA, Russell SR, et al. Missense variations in the fibulin 5 gene and age-related macular degeneration. $N$ Engl J Med. 200422;351(4):346-53. 